\title{
SISTEMAS INTEGRADOS DE PRODUÇÃO - O NOVO DESAFIO PARA A AGROPECUÁRIA BRASILEIRA
}

Ricardo Augusto da Silva ${ }^{1}$, José Eduardo Creste ${ }^{1}$, Moacir José Sales Medrado ${ }^{2}$, Isabela Marega Rigolin $^{1}$

${ }^{1}$ Universidade do Oeste Paulista - UNOESTE, Presidente Prudente - SP. ${ }^{2}$ Diretor Geral MCA - Medrado \& Consultores Agroflorestais Associados, Curitiba - PR. E-mail: ras-campomourao@hotmail.com

\section{RESUMO}

A agropecuária brasileira se destaca como uma atividade, que além de ser fundamental para a economia (superávit da balança comercial) é também extremamente importante para o desenvolvimento econômico, social e ambiental do país. O Produto Interno Bruto (PIB) do Brasil no ano de 2010 chegou a $\mathrm{R} \$ 3,675$ trilhões, sendo que deste valor 6,5 \% (R\$ 180,80 bilhões) são oriundos da agropecuária (IBGE, 2011). Ressalta-se assim a importância do setor para o desenvolvimento do Brasil. O objetivo desta revisão é o de discutir a utilização das várias formas de Integração Lavoura-Pecuária-Floresta (ILPF) para a agropecuária brasileira, como forma de garantir o destaque e a competitividade do setor. A Integração Lavoura-Pecuária-Floresta (ILPF) é um sistema que, além de adequar as atividades agropecuárias existentes aos moldes relacionados à questão ambiental, proporciona aumento da rentabilidade da agropecuária, fixando o homem no campo e diminuindo o êxodo rural. Porém, há necessidade do aumento de pesquisas relacionadas a ILPF, visando uma harmonização do sistema e máxima produção.

Palavras - chave: sistemas agroflorestais, sistema silvipastoril, sombreamento, sistema agrossilvipastoril.

\section{INTEGRATED PRODUCTION SYSTEMS - THE NEW CHALLENGE FOR BRAZILIAN AGRICULTURE}

\begin{abstract}
The Brazilian agricultural sector stands out as an activity, which besides being fundamental to the economy (trade surplus) is also extremely important to the economic, social and environmental situation. The Gross Domestic Product (GDP) of Brazil came in 2010 at R \$ 3.675 trillion, and this value agriculture accounts for $6.5 \%$ ( $R \$ 180.80$ billion) (IBGE, 2011), thus underscoring the sector's importance to the development of Brazil. Thus, the purpose of this review is to discuss the use of various forms of Integrated Crop-Livestock-Forest (ILPF) for Brazilian agriculture as a way to ensure the prominence and competitiveness of the sector. The Crop-Livestock Integration-Forest (ILPF) is a system that, in addition to adapting the existing agricultural activities practiced by Brazilian farmers, the templates related to environmental issues, especially in the neutralization of the gases emitted by livestock and agriculture to help accelerate the process of global warming may also increase the profitability of agriculture and settle in the field, reducing the rural exodus. However, there is need for increased research related to ILPF system, aiming at harmonization and maximum production.
\end{abstract}

Keywords: system agroforestry, system silvopastoral, shading, system agrossilvipastoril. 


\section{INTRODUÇÃO}

A agropecuária brasileira se destaca como uma atividade, que além de ser fundamental para a economia (superávit da balança comercial) é também extremamente importante para o desenvolvimento econômico, social e ambiental do país. O Produto Interno Bruto (PIB) do Brasil no ano de 2010 chegou na casa dos R\$ 3,675 trilhões, sendo que deste valor a agropecuária foi responsável por 6,5\% (R\$ 180,80 bilhões) (IBGE, 2011), ressaltando assim a importância do setor para o desenvolvimento do Brasil.

Já no caso específico do Estado do Paraná, o PIB alcançou em 2010 os R\$ 220.368,00 milhões, o que representa cerca de $6 \%$ do PIB brasileiro (KURESKI, 2011). A agropecuária paranaense teve no ano de 2009 um Valor Bruto de Produção (VBP) de $R \$ 37,4$ bilhões (DERAL, 2010), que engloba a produção da agricultura, pecuária e florestal. Para que essas cadeias produtivas continuem se destacando e mantendo o nível de importância na economia, faz-se necessário a utilização de agrotecnologias viáveis do ponto de vista econômico, social e ambiental.

Dentro da gama de tecnologias existentes, a Integração Lavoura-PecuáriaFloresta (ILPF) se configura como um sistema que combina a utilização de espécies agrícolas, da pecuária e da floresta numa mesma área e, de forma simultânea ou escalonada no tempo (HUDSON; GARCIA, 2010). Este sistema se configura como uma estratégia agroecológica, que visa aplicar manejos voltados à manutenção dos solos biologicamente ativos, assegurando boas colheitas com baixos custos financeiros e ambientais (PETERSEN; WEID; FERNANDES, 2009).

O objetivo dessa revisão foi expor a utilização das várias formas de integração da agricultura, pecuária e floresta como forma de garantir o destaque e a competitividade quando estes setores forem integrados.

\section{SISTEMAS INTEGRADOS DE PRODUÇÃO}

A Integração Lavoura-PecuáriaFloresta (ILPF) é uma modalidade que está inserida dentro dos Sistemas Agroflorestais (SAF's), que pode englobar culturas agrícolas, florestais e ou animais, simultaneamente ou não.

Os Sistemas Agroflorestais (SAF's) são aqueles que integram na mesma área culturas agrícolas com espécies florestais e/ou animais e tem por objetivo a otimização do uso do solo e dos recursos naturais, visando sempre a máxima produtividade do sistema, seguindo o princípio da conservação dos recursos naturais utilizados (solos, água, florestas nativas). De acordo com Camargo e Macedo (1994) o manejo adequado da 
composição e estrutura dos sistemas agroflorestais permite potencializar algumas das suas vantagens intrínsecas, principalmente aquelas relacionadas aos aspectos biológicos e físicos.

De acordo com os componentes e espécies cultivadas em integração, os Sistemas Agroflorestais (SAF's) podem ser classificados, conforme Oliveira (2005) como:

A) Sistemas Silviagrícolas ou Agrossilviculturais: caracterizados pelo consórcio de árvores com cultivos agrícolas anuais ou perenes;

B) Sistemas Silvipastoris (SSP's): preconizados pela consorciação de árvores, dentro da atividade pecuária, ou a criação de animais dentro de povoamentos florestais;

C) Sistemas Agrossilvipastoris (ILPF): caracterizados pela combinação do componente arbóreo com cultivos agrícolas e criação de animais, de maneira simultânea ou seqüencial.

\section{SISTEMAS}

AGROSSILVICULTURAIS

\section{(Integração Lavoura-Floresta)}

Os sistemas agrossilviculturais (Integração Lavoura-Floresta) integram o cultivo de lavouras anuais ou perenes com espécies florestais.

Exemplos de sistemas de integração Lavoura-Floresta podem ser encontrados na integração de café com seringueira. As vantagens deste sistema utilizando a seringueira no consórcio, além do ponto de vista econômico (incremento de produção de borracha), implica na redução de custos com a formação do seringal, melhoria da eficiência da ciclagem de nutrientes através da diferença de níveis de exploração do solo pelos sistemas radiculares da seringueira e café, melhor aproveitamento da radiação luminosa incidente e cobertura (proteção do solo) pelas partes aéreas (PEREIRA et al., 1994).

A integração entre café e seringueira apresenta grande potencial para regiões produtoras de café do Paraná, pois além de gerar uma renda alternativa com a produção de borracha, reduz a temperatura das folhas do cafeeiro e também protege as plantas contra a geada, proteção propiciada pelas copas das árvores (LEAL et al., 2011).

Martins e Coelho (1994) citam o exemplo da implantação do sistema agroflorestal (SAF) no início do reflorestamento com Araucária angustifolia (Araucária) com arroz e milho no Sudoeste do Paraná. A principal vantagem no uso da consorciação é a redução no custo de manutenção do povoamento florestal, com uma média de 38\%.

O consórcio de lavouras anuais (soja, milho, feijão, arroz, aveia) cultivadas entre renques de espécies do gênero Eucalyptus plantados nas costas dos terraços em nível, representam uma proposta integrada de uso 
das terras, resultando na melhoria da qualidade dos recursos ambientais, graças as interações ecológicas e econômicas que ocorrem nesse processo (SILVA; SILVA; MENARIM FILHO, 2009).

A Integração Lavoura-Floresta também pode ser realizada utilizando

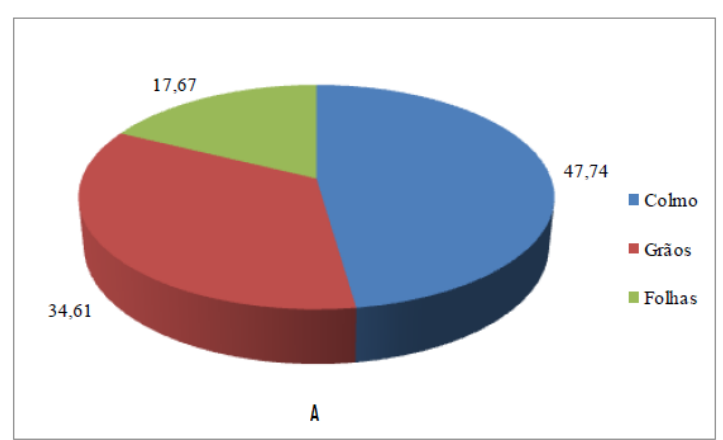

eucalipto com sorgo e girassol, cuja produção das culturas do girassol, sorgo e eucalipto (16 meses pós-plantio) apresentaram valores de 2549, 3417 e $4969 \mathrm{~kg} \mathrm{ha}^{-1}$, respectivamente (CALIL, 2008), conforme Figura 1 e Tabela 1.

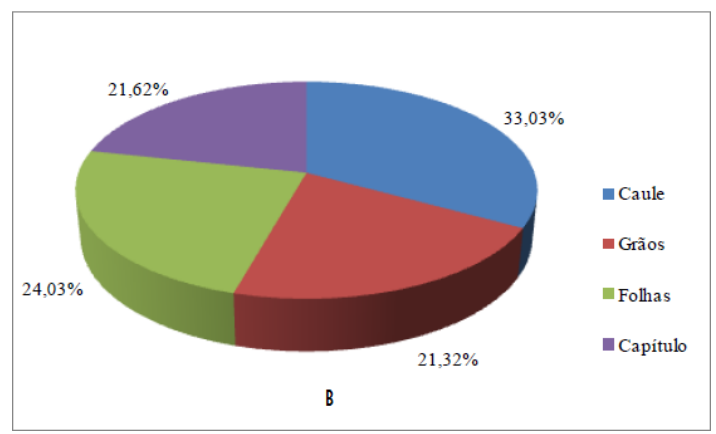

Figura 1. Distribuição percentual de biomassa acima do solo nas culturas do sorgo (Sorghum bicolor) (A) safra 2006 e girassol (Helianthus annus) (B) safra 2007 em sistema agroflorestal, Candiota - RS. Fonte: Calil (2008).

Tabela 1. Distribuição percentual dos componentes da biomassa acima do solo de Eucalyptus urograndis, aos 16 meses.

\begin{tabular}{ccc}
\hline Componente & Biomassa $\left(\mathrm{kg} \mathrm{ha}^{-1}\right)$ & $\%$ \\
\hline Madeira & $4.969,50$ & 45,28 \\
Galhos & $2.886,90$ & 26,31 \\
Casca & 927,05 & 8,45 \\
Folhas & $2.190,82$ & 19,96 \\
\hline TOTAL & $10.974,27$ & 100 \\
\hline
\end{tabular}

Fonte: Calil (2008).

SISTEMAS SILVIPASTORIS (Integração

\section{Pecuária - Floresta)}

A arborização das pastagens é uma modalidade de Sistemas Agroflorestais (SAF's) denominado Sistema Silvipastoril ou
Integração Pecuária-Floresta, que arranja de forma intencional árvores, animais e pastagem numa mesma área, conforme Figura 2. 
Esse sistema proporciona um aumento de renda devido a produção de madeira e aumento na produção animal. Porfírio-da-Silva e Mazuchowski (1999) relataram que em área com sistema silvipastoril no município de Tapejara - PR, com população de 198 árvores aos 14 anos de idade, havia taxa de lotação de 2,1 cabeças por hectare, representando lotação $66,7 \%$ superior a média obtida no município (1,4 cabeças por hectare). Além disso, na mesma área foram produzidos 122 metros cúbicos de madeira (toras de 6 metros de comprimento) e 118,8 metros estéreos de lenha.

A Integração Pecuária - Floresta também implica em benefícios das árvores sobre a produtividade das pastagens, através do aumento da disponibilidade de nitrogênio (N) no solo, bem como, do aumento de matéria orgânica pela deposição das folhas e ramos das árvores. Além disso, as árvores proporcionam outros benefícios como o aumento da taxa de lotação, controle de erosão, menor frequência de reforma de pastagens, melhoria das condições ambientais, proporcionando conforto animal e melhoria dos índices produtivos e reprodutivos dos animais. Ainda, as árvores contribuem para o seqüestro de carbono, redução da emissão de óxido nitroso $\left(\mathrm{N}_{2} \mathrm{O}\right)$ e mitigação da emissão de gás metano $\left(\mathrm{CH}_{4}\right)$ pelos ruminantes (PORFÍRIO-DA-SILVA et al., 2009).

Menarim Filho (2007) observou que a associação de renques de eucalipto a pastagens de Brachiaria é uma prática viável para a região Noroeste do Estado do Paraná, pois mantiveram o potencial produtivo $\mathrm{e}$ melhoraram a qualidade nutricional da forragem. Já a associação de renques de eucalipto a pastagens de Cynodon melhora a qualidade nutricional da forragem e propicia condições climáticas favoráveis ao desenvolvimento animal, porém faz-se necessário atentar para os espaçamentos utilizados entre os renques $(15 \times 2,20 \times 2 \mathrm{e}$ $25 \times 2$ metros).

Um fator que deve ser manejado de forma correta no sistema silvipastoril é o sombreamento, pois se for muito intenso reduz em $81 \%$ da produção de forragem das espécies forrageiras (KIRCHNER et al, 2010). Martuscello et al. (2009), observaram que a produtividade do capim-braquiária (Brachiaria decumbens) aumenta quando submetida a $50 \%$ de sombreamento. Isso indica que essa planta é resistente à sombra, apresentando aumento nos teores de proteína bruta, redução dos de fibra em detergente neutro e maior digestibilidade in vitro da matéria seca (PACIULLO et al, 2007).

Soares et al. (2009), observaram o efeito da luminosidade no comportamento de onze espécies forrageiras de verão. As 
plantas sombreadas apresentam melhor qualidade (maior teor de proteína bruta na lâmina foliar e maior relação lâmina foliar/colmo), embora a produção de matéria seca seja menor com a presença de árvores. Para que o sombreamento do sistema não afete demasiadamente a produção das forrageiras, faz-se necessária a realização da desrama, no qual se retira os galhos das árvores com DAP maior que $6 \mathrm{~cm}$, visando controlar o sombreamento e garantir a qualidade das árvores.

A utilização do sistema silvipastoril não isenta o produtor da aplicação de tecnologias já existentes relacionadas a atividade pecuária como adubações e manejo das pastagens e manejo dos animais (sanitário e reprodutivo). Bernardino (2007), observou que a aplicação de fertilizante nitrogenado aumentou a disponibilidade de matéria seca da Brachiaria brizantha cv. Marandu entre sub-bosques de eucalipto, elevando sua capacidade suporte e o ganho de peso animal por unidade de área.

O sistema silvipastoril tem sido utilizado com mais frequência por pecuaristas que tem a atividade da bovinocultura de leite como a principal fonte de renda da propriedade. Geralemnte, a maioria dos produtores de leite estruturados possui bom planejamento forrageiro, rebanhos com índices de melhoramento genético elevados e práticas adequadas de manejo. Mesmo assim, quase sempre faltam cuidados com o conforto animal para que a exploração seja mais produtiva. Benedetti (2008) relata que a queda na produção leiteira pode chegar a $57 \%$, entretanto, isso não ocorre, pois boa parte da reserva corporal é consumida para atender à produção de leite, sendo que a sombra pode melhorar a produção em torno de $14 \%$, além de preservar a reprodução (SILVA et al., 2010).

Também, verifica-se a grande oportunidade da pecuária leiteira em participar, com inúmeras vantagens, nos sistemas integrados de produção, em especial, visando a diminuição dos custos de produção do leite em função, basicamente, de maior disponibilidade de alimentos em quantidade e qualidade (ROCHA et al., 2010).

\section{SISTEMAS AGROSSILVIPASTORIS (Integração Lavoura-Pecuária-Floresta)}

O sistema agrossilvipastoril ou integração lavoura-pecuária-floresta (ILPF) é aquele que engloba a combinação do componente arbóreo com cultivos agrícolas e criação de animais, de maneira simultânea ou seqüencial, conforme a Figura 2. 

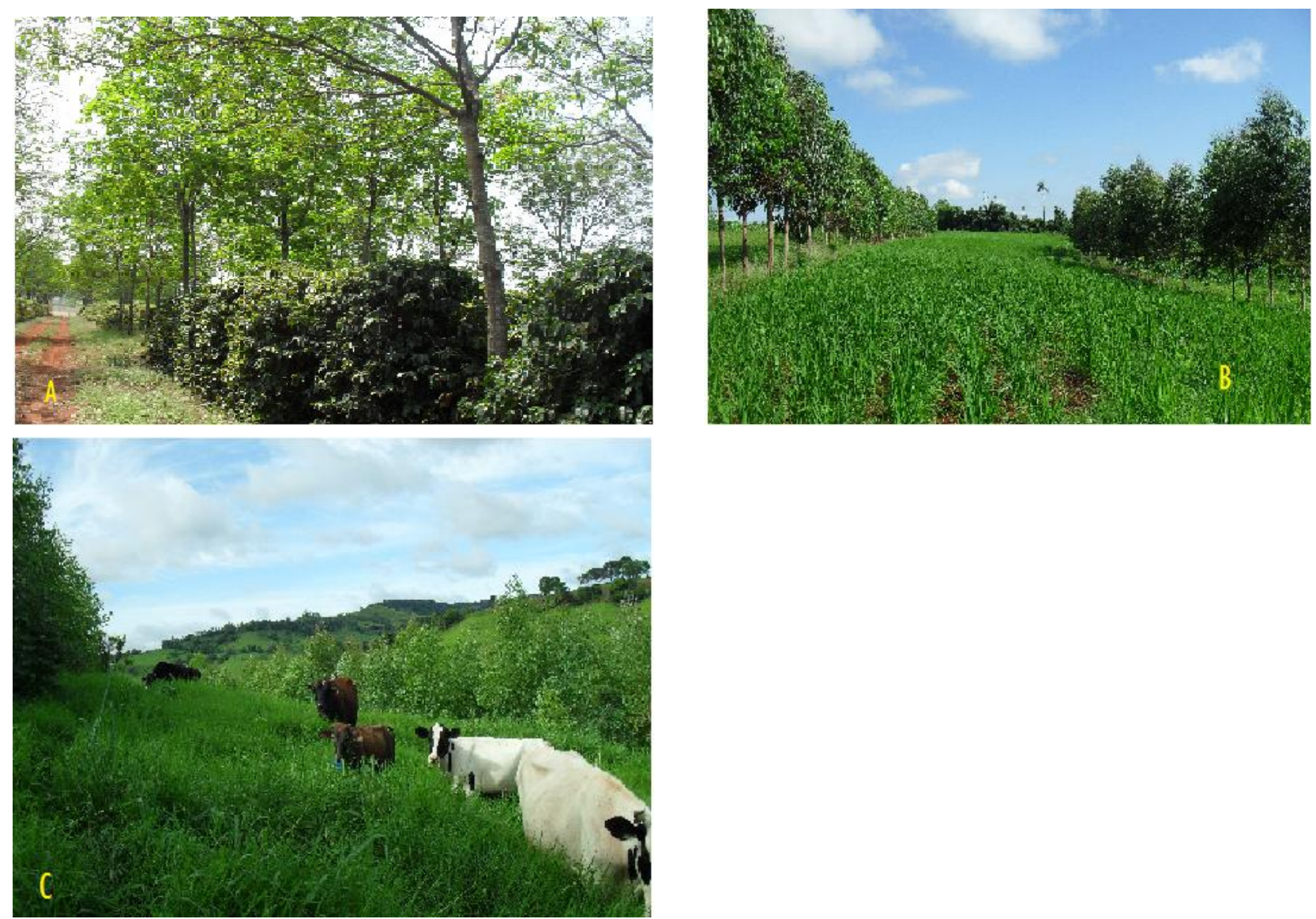

Figura 2. Sistema Agrossilvicultural Café - Seringueira (A), Lavoura - Floresta (B) e Sistema Silvipastoril (C). Fonte: Silva et al (2010). Fonte: Silva et al (2010).

A ILPF em sua versão plena (integral) ou sistemas como lavoura/pecuária, lavoura/floresta e pecuária/floresta, devem ser entendidos como estratégia de estímulo e apoio rumo a sustentabilidade (ROMANO, 2010), pois além de conferir bons resultados econômicos e sociais, vários e nobres serviços ambientais são prestados à sociedade pelos produtores que adotam tal sistema.

Os ganhos ambientais mais evidentes, conforme Romano (2010) são: seqüestro de carbono com redução da emissão de gases de efeito estufa; recuperação da qualidade e da capacidade produtiva do solo; maior infiltração de água das chuvas, redução do processo erosivo; menor incidência de pragas, doenças e plantas daninhas; bemestar animal pelo microclima ameno gerado pelo componente florestal e, principalmente, a diversificação da produção e minimização dos riscos climáticos e de mercado.

Os benefícios gerados pelos sistemas agrossilvipastoris ao meio ambiente são comprovados nas mais diversas regiões do mundo. No município de Sobral - CE, o 
sistema agrossilvipastoril

mostrou-se

eficiente na ciclagem de nutrientes e permitiu recomendar o sistema silvipastoril para a manutenção da qualidade do solo e produção de alimentos na região do semiárido cearense (MAIA et al., 2006).

Segundo Galzerano e Morgado (2008), em experimento realizado no Noroeste de Minas Gerais utilizando o cultivo de eucalipto com arroz (o arroz foi semeado em consórcio com mudas de eucalipto) e na segunda sucessão eucalipto com soja, finalizando a com a implantação de pastagem, no ano dois do sistema, foi possível concluir que há um aumento no estoque de carbono com o passar dos anos, auxiliando no controle da erosão. Portanto, os sistemas agrossilvipastoris permitem 0 abatimento da erosão, se comparados com uma pastagem degradada (RIBEIRO et al., 2007).

Por ser um sistema de produção, a ILPF requer alguns cuidados relacionados ao manejo da fertilidade e adubação das culturas no sistema (lavouras anuais, forrageiras e florestais). A falta de informações pode levar a recomendações de correção de solo e adubação apenas para as culturas anuais e para a pastagem. $\mathrm{O}$ eucalipto, embora componente do sistema ILPF, por ser uma espécie florestal com características bastante distintas, tem sua recomendação de adubação particular, independentemente do referido sistema (FREIRE et al, 2010).

Apesar dos benefícios, o sucesso do funcionamento dos sistemas agrossilvipastoris está sujeito ao conhecimento das interações entre os seus componentes, permitindo a geração de estratégias de gestão apropriadas a cada situação (MOTA, 2010). OLIVEIRA et al., (2007) verificaram, que, independente do arranjo do plantio do eucalipto, a disponibilidade de forragem foi sempre maior na entrelinha do que na linha de plantio. Entretanto, o sombreamento estimula a resposta de alongamento das folhas das espécies de brachiarias devido à aplicação de nitrogênio, porém reduz o perfilhamento das mesmas (PACIULLO et al, 2011), ressaltando a importância do manejo de luz para a manutenção do sistema.

Vale ressaltar que esse sistema é muito interessante, pois otimiza o uso da terra, uma vez que os custos das atividades também são diluídos porque um mesmo tratamento cultural serve para mais de uma cultura e que o lucro descontado do sistema foi de $\mathrm{R} \$ 15.970,17$ por hectare, o que se equivale a um lucro anual de $\mathrm{R} \$ 2.310,00$ por hectare, indicando a viabilidade econômica do projeto de ILPF (CORDEIRO; SILVA, 2010).

Por fim, a introdução de espécies arbóreas no sistema ILP é uma opção desejável, pois além de dar ao produtor rural 
mais uma alternativa de renda, pelo uso ou comercialização da madeira produzida, pesquisas recentes têm mostrado que 0 sombreamento de pastagens contribui para um aumento da produtividade do rebanho (SOUZA, 2007).

\section{INTEGRAÇÃO LAVOURA-PECUÁRIA (ILP)}

O sistema de integração lavourapecuária (ILP) é definido como a produção de grãos, carne e leite em colaboração mútua (SÁ, 2006), em épocas diferentes do ano, resultando em um melhor uso da terra com agregação de valor à propriedade (KOZELINSKI, 2009).

Os inúmeros e incontáveis benefícios da ILP podem ser condensados como: recuperação e manutenção das características produtivas do solo (agronômicos); diversificação de oferta e obtenção de maiores rendimentos a um menor custo e com maior qualidade (econômicos); redução da biota nociva às espécies cultivadas e conseqüente redução de defensivos agrícolas e de erosão (ecológicos) e atividades pecuárias e lavoureiras que concentram e distribuem renda (sociais), além da fixação do homem no campo (KLUTHCOUSKI; AIDAR; COBUCCI, 2007). Para que esses benefícios sejam potencializados, a nova tendência dos sistemas de integração lavoura-pecuária é a incorporação de árvores, configurando o que se chama de Integração Lavoura-PecuáriaFloresta (ILPF) (MACEDO, 2009). Salienta-se entretanto que em áreas com vocação agrícola, o componente floresta não tem necessidade de ser incluso.

Por ser um sistema que maximiza a produção, o sistema de integração lavourapecuária tem seus processos de produção, exportação e ciclagem de nutrientes acelerados, principalmente na fase inicial de implantação, elevando a demanda por nutrientes, ou seja, fertilizantes, ressaltando que as áreas destinadas a esse sistema não devem ser áreas marginais da propriedade agrícola (ASSMANN; ASSMANN; ASSMANN, 2008). Além disso, o solo sob integração lavoura-pecuária tem potencial para ser dreno de carbono (C) atmosférico, desde que no inverno seja adotado um intervalo de pastejo de 28 dias e evite-se monocultura de soja no verão (NICOLOSO et al., 2008).

Assmann et al. (2004) concluíram, mediante resultado de experimento realizado no município de Guarapuava - PR, que o consórcio de gramíneas (aveia + azevém) com leguminosa de estação fria possibilita o aumento do período de pastejo e, consequentemente, resulta em um melhor rendimento animal no sistema integração lavoura-pecuária, porém, a Integração Lavoura-Pecuária não promove melhoria da qualidade física do solo (ARAÚJO et al., 2010). 
Spera et al. (2010) concluíram, após realização de experimento em Coxilha - RS, que durante os três anos avaliados não houve efeito desfavorável do pisoteio animal sobre a estrutura da superfície do solo e que o pisoteio pelos bovinos, nos sistemas de produção integrando lavoura e pecuária estudados, não proporcionaram compactação do solo em níveis considerados críticos a produção vegetal. Mas, se o manejo do sistema não for adequado, o estabelecimento da cultura da soja é negativamente afetado com o decréscimo da palhada residual que se transfere ao ciclo da lavoura, oriunda das diferentes intensidades de pastejo empregadas no ciclo da pastagem antecedente (LOPES et al., 2009).

Porém, para que se obtenham os melhores resultados, a eficiência na adubação será obtida quando existir sincronia entre o suprimento de nutrientes pelo solo, pela ciclagem e pela adubação, privilegiando o sistema de produção como um todo (adubação de sistema) (ANGHINONI; ASSMANN, 2011).

Apesar de todos os benefícios da ILP, a adoção da tecnologia pelos agricultores ainda é um desafio, no que diz respeito à adequação do sistema as atividades agropecuárias que o produtor pratica, sendo que é recomendável que a ILP seja conduzida em sistema conservacionista de uso dos solos, de preferência em plantio direto, visando manter o solo com cobertura vegetal (FERREIRA, 2009).

\section{CONSIDERAÇÕES FINAIS}

Os sistemas integrados de produção são sistemas que, além de adequar as atividades agropecuárias existentes praticadas pelos agricultores brasileiros aos moldes relacionados à questão ambiental, em especial, na neutralização dos gases emitidos pela pecuária e agricultura que ajudam a acelerar $o$ processo de aquecimento global, podem ainda aumentar a rentabilidade da agropecuária e fixar o homem no campo, diminuindo o êxodo rural.

Apesar dos avanços que já conquistados com uso de sistemas integrados, há necessidade do aumento de pesquisas relacionadas ao manejo de fertilidade, plantas daninhas, pragas, doenças e das culturas e criações presentes no sistema, visando uma harmonização e máxima produção dos componentes integrantes.

\section{REFERÊNCIAS}

ARAÚJO, F. S; SALVIANO, A. A. C; LEITE, L. F. C; SOUZA, Z. M; SOUZA, A. C. M. de. Physical quality of a yellow latossol under integrated crop-livestock system. Revista Brasileira de Ciência do Solo. Viçosa, v. 34, p. 717 - 723, 2010.

ANGHINONI, I; ASSMANN, J. M. Ciclagem de nutrientes em sistema de integração soja pecuária de corte em plantio direto e 
implicações na adubação. Piracicaba, SP: International Plant Nutrition Institute Brasil, 2011, p. 1 - 10 (Informações Agronômicas n ${ }^{\circ}$ 136).

ASSMANN, A. L; PELISSARI, A; MORAES, A. de; ASSMANN, T. S; OLIVEIRA, E. B. de; SANDINI, I. Produção de Gado de Corte e Acúmulo de Matéria Seca em Sistema de Integração Lavoura-Pecuária em Presença e Ausência de Trevo Branco e Nitrogênio. Revista Brasileira de Zootecnia. Viçosa, v. 33, n. 1, p. $37-44$, 2004.

ASSMANN, T. S; ASSMANN, A. L; ASSMANN, J. $M$. Ciclagem de nutrientes e adubação. In: ASSMANN, A. L; SOARES, A. B; ASSMANN, T. S (eds). Integração lavoura-pecuária para a agricultura familiar. Londrina, PR: IAPAR, $p$. $16-24,2008$.

BENEDETTI, E. Bases práticas para a produção de leite a pasto. Uberlândia, MG: EDUFU, 212p, 2008.

BERNARDINO, F. S. Sistema silvipastoril com eucalipto: produtividade do sub-bosque e desempenho de novilhos sob fertilização nitrogenada e potássica. 2007. 112p. Tese (Doutorado) - Universidade Federal de Viçosa (UFV), Viçosa - MG.

CALIL, F. N. Aspectos Nutricionais de um Sistema Agroflorestal com Eucalipto no Sul do Rio Grande do Sul, Brasil. 2008. 144p. Tese (Doutorado) - Universidade Federal de Santa Maria (UFSM), Santa Maria - RS.

CAMARGO, I. P; MACEDO, R. L. G. Sistemas agroflorestais no contexto do desenvolvimento sustentável. In: MONTOYA, L. J; MEDRADO, M. J. S (eds). Anais do I CONGRESSO BRASILIEIRO SOBRE SISTEMAS AGROFLORESTAIS. Colombo, PR: EMBRAPACNPF, p. 43 - 51, 1994.

CORDEIRO, S. A; SILVA, M. L. da. Análise técnica e econômica de Sistemas Agrossilvipastoris. In: OLIVEIRA NETO, S. N. de; VALE, A. B. do; NACIF, A. de P; VILAR, M. $B ; A S S I S$, J. B. de. Sistema Agrossilvipastoril: integração lavoura, pecuária e floresta. Viçosa, MG: Sociedade de Investigações Florestais (SIF), p. 167 - 189, 2010.

DERAL. Valor Bruto da Produção Agropecuária Paranaense 2009. Disponível em:

<http://www.seab.pr.gov.br/arquivos/File/de ral/VBP2009.pdf> Acesso em: 16 abr. 2011.

FERREIRA, E. V. de O. Dinâmica de potássio em sistema de integração lavoura-pecuária em plantio direto sob intensidades de pastejo. 2009, 84p. Dissertação (Mestrado) Universidade Federal do Rio Grande do Sul (UFRGS), Porto Alegre - RS.

FREIRE, F. M; COELHO, A. M; BARROS, N. F. de; BARROS FILHO, N. F. de; NEVES, J. C. L. Manejo da fertilidade do solo no Sistema Integração Lavoura-Pecuária-Floresta. Belo Horizonte, MG: EPAMIG, 2010, v. 31, p. 25 36, jul./ago (Informe Agropecuário 257).

GALZERANO, L; MORGADO, E. Eucalipto em Sistemas Agrossilvipastoris (Eucalyptus and Agricultural-forestry-pasture Systems). Revista Electrónica de Veterinaria. Málaga, Espanã: vol. IX, $\mathrm{n}^{\circ}$ 3, p. $1-6$, mar. 2008. Disponível em: < http://www.veterinaria.org/revistas/redvet/ n030308/030818.pdf> Acesso em: 16 abr. 2011.

HUDSON, L. S; GARCIA, M. A. Sistema Agrossilvipastoril - Uma opção de Rentabilidade e Sustentabilidade. Disponível em:

http://www.exagro.com.br/biblioteca/sistem a-agrosilvipastoril.pdf> Acesso em: 16 abr. 2011.

IBGE. Em 2010, PIB varia 7,5\% e fica em $R \$$ 3,675 trilhões (comunicação social) . Disponível em: <http://www.ibge.gov.br/home/presidencia/ 
noticias/noticia_visualiza.php?id_noticia $=183$ 0\&id_pagina=1> Acesso em: 16 abr. 2011.

KIRCHNER, R; SOARES, A. B; SARTOR, L. R; ADAMI, P. F; MIGLIORINI, F; FONSECA, L. Desempenho de forrageiras hibernais sob distintos níveis de luminosidade. Revista Brasileira de Zootecnia. Viçosa, v. 39, n. 11, p. $2371-2379,2010$.

KLUTHCOUSKI, J; AIDAR, H; COBUCCI, T. Opções e vantagens da Integração LavouraPecuária e a produção de forragens na entressafra. Belo Horizonte, MG: EPAMIG, 2007 , v. 28 , p. 16 - 29, set./out. (Informe Agropecuário 240).

KOZELINSKI, S. M. Produção de trigo duplo propósito e ciclagem de nutrientes em sistema de integração lavoura pecuária. 2009, 90p. Dissertação (Mestrado) Universidade Tecnológica Federal do Paraná campus Pato Branco (UTFPR), Pato Branco PR.

KURESKI, R. O PIB Paranaense em 2010. Análise conjuntural, v. 33, n.1 - 2, jan/fev $2011 . \quad$ Disponível em: <http://www.ipardes.pr.gov.br/biblioteca/do cs/bol_33_1d.pdf> Acesso em: 16 abr. 2011.

LEAL, A. C; CARAMORI, P. H; ANDROCIOLI FILHO, A; PEREIRA, J. de P. Consórcio Agroflorestal Café $X$ Seringueira em Londrina (PR): Efeito na Produtividade e na Temperatura das Folhas de Café. Disponível em:

<http://www.iapar.br/arquivos/File/zip_pdf/ cafe\%20e\%20seringueira.pdf $>$ Acesso em: 16 abr. 2011.

LOPES, M. L. T; CARVALHO, P. C. de F; ANGHINONI, I; SANTOS, D. T. dos; AGUINAGA, A. A. Q; FLORES, J. P. C; MORAES, A. de. Sistema de integração lavourapecuária: efeito do manejo de altura em pastagem de aveia preta e azevém anual sobre o rendimento da cultura da soja.
Ciência Rural. Santa Maria, v. 39, n. 5, p. 1499 - 1506, 2009.

MACEDO, M. C. M. Integração lavourapecuária: o estado da arte e inovações tecnológicas (suplemento especial). Revista Brasileira de Zootecnia. Viçosa, v. 38, p. 133 -146, 2009.

MAIA, S. M. F; XAVIER, F. A. da S; OLIVEIRA, T. S. de; MENDONÇA, E. de S; ARAÚJO FILHO, J. A. Impactos de sistemas agroflorestais e convencional sobre a qualidade do solo no semi-árido cearense. Revista Árvore. Viçosa: v. 30, n. 5, p. $837-848,2006$.

MARTINS, S. S; COELHO, V. C. M. O uso do sistema agroflorestal na Região Sudoeste do Estado do Paraná. In: Anais do I ENCONTRO SOBRE SISTEMAS AGROFLORESTAIS NOS PAÍSES DO MERCOSUL. Porto Velho, RO: EMBRAPA-CNPF, p. 173 - 180, 1994.

MARTUSCELLO, J. A; JANK, L; GONTIJO NETO, M. M; LAURA, V. A; CUNHA, D. de N. F. V. da. Produção de gramíneas do gênero Brachiaria sob níveis de sombreamento. Revista Brasileira de Zootecnia. Viçosa, v. 38, n. 7, p. 1183 - 1190, 2009.

MENARIM FILHO, A. Produção e composição química de forragens em sistema silvipastoril com Eucalyptus spp. 2007. 61p. Dissertação (Mestrado) - Universidade Estadual de Maringá (UEM), Maringá - PR.

MOTA, V. A. Integração Lavoura-PecuáriaFloresta na recuperação de pastagens degradadas no Norte de Minas Gerais. 2010. 112p. Dissertação (Mestrado) - Universidade Federal de Minas Gerais (UFMG), Montes Claros - MG.

NICOLOSO, R. da S; LOVATO, T; AMADO, T. J. C; BAYER, C; LANZANOVA, M. E. Balanço do carbono orgânico no solo sob integração lavoura-pecuária no Sul do Brasil. Revista Brasileira de Ciência do Solo. Viçosa, v. 32, p. 2425 - 2433, 2008. 
OLIVEIRA, T. K. de. Sistema Agrossilvipastoril com eucalipto e braquiária sob diferentes arranjos estruturais em área de Cerrado. 2005. 150p. Tese (Doutorado) - Universidade Federal de Lavras (UFLA), Lavras - MG.

OLIVEIRA, T. K. de; MACEDO, R. L. G; SANTOS, I. P. A. dos; HIGASHIKAWA, E. M; VENTURIN, N. Produtividade de Brachiaria brizantha (Hochst. ex. A. Rich.) Stapf cv. Marandu sob diferentes arranjos estruturais de sistema agrossilvipastoril com eucalipto. Ciência e Agrotecnologia. Lavras, v. 31, n. 3, p. $748-$ 757, 2007.

PACIULLO, D. S. C; CARVALHO, C. A. B. de; AROEIRA, L. J. M; MORENZ, M. J. F; LOPES, F. C. F; ROSSIELLO, R. O. P. Morfofisiologia e valor nutritivo do capim-braquiária sob sombreamento natural e a sol pleno. Pesquisa Agropecuária Brasileira. Brasília, DF, v. 42, n. 4, p. 573 - 579, abr. 2007.

PACIULLO, D. S. C; FERNANDES, P. B; GOMIDE, C. A. de M; CASTRO, C. R. T. de; SOUZA SOBRINHO, F. de; CARVALHO, C. A. B. de. The growth dynamics in Brachiaria species according to nitrogen dose and shade. Revista Brasileira de Zootecnia. Viçosa, , v. 40, n. 2, p. $270-276,2011$.

PEREIRA, J. de P; ANDROCIOLI FILHO, A; LEAL, A. C; RAMOS, A. L. M. Consorciação de seringueira e cafeeiro em fase terminal e o seu efeito na redução do período de imaturidade do seringal. In: MONTOYA, L. J; MEDRADO, M. J. S (eds). Anais do I CONGRESSO BRASILIEIRO SOBRE SISTEMAS AGROFLORESTAIS. Colombo, PR: EMBRAPACNPF, p. $103-112,1994$.

PETERSEN, P. F; WEID, J. M. V. D; FERNANDES, G. B. Agroecologia: reconciliando agricultura e natureza. Belo Horizonte, MG: EPAMIG, 2009, v. 30, p. 7 15, set./out. (Informe Agropecuário 252).
PORFÍRIO-DA-SILVA, V; MAZUCHOWSKI, J. Z. Sistemas Silvipastoris: paradigma dos pecuaristas para agregação de renda e qualidade. Curitiba, PR: EMATER-PR, 52p (Série Informação Técnica, 50), 1999.

PORFÍRIO-DA-SILVA, V; MEDRADO, M. J. S; NICODEMO, M. L. F; DERETI, R. M. Arborização de pastagens com espécies florestais madeireiras: implantação e manejo. Colombo, PR: EMBRAPA Florestas, 48p, 2009.

RIBEIRO, S. C; CHAVES, H. M. L; JACOVINE, L. A. G; SILVA, M. L. da. Estimativa do abatimento de erosão aportado por um sistema agrossilvipastoril e sua contribuição econômica. Revista Árvore. Viçosa, v. 31, n. 2, p. $285-293,2007$.

ROCHA, W. S. D. da; MULLER, M. D SOUZA SOBRINHO, F; MARTINS, C. E; BRIGHENTI, A. $M$; ANDRADE, P. J. M. Pecuária de leite na Integração Lavoura-Pecuária-Floresta. Belo Horizonte, MG: EPAMIG, 2010, v. 31, p. $70-$ 80, jul./ago. (Informe Agropecuário 257).

ROMANO, P. A. Integração LavouraPecuária-Floresta: uma estratégia para a sustentabilidade. Belo Horizonte, MG: EPAMIG, 2010, v. 31, p. 7 - 15, jul./ago. (Informe Agropecuário 257).

SÁ, J. P. G. Integração Lavoura e Pecuária. In: CASÃO JUNIOR, R; SIQUEIRA, R; MEHTA, Y. R; PASSINI, J. J. Sistema plantio direto com qualidade. Londrina, PR: IAPAR; Foz do Iguaçu, PR: ITAIPU Binacional, p.127 - 135, 2006.

SILVA, R. A. da; SILVA, J. M. da; MENARIM FILHO, A. O benefício dos sistemas agroflorestais (SAF's) para a agropecuária brasileira. Revista Meio Ambiente. Campo Mourão, número XVIII, p. 37 - 38, 2009.

SILVA, R. A.; SILVA, J. M; MENARIM FILHO, A; ASAMI, K. O; SILVA, L. V; MEDRADO, M. J. S; DERETI, R. M. Projeto melhora conforto e 
produção. Revista Balde Branco. São Paulo, n. 547, p. 71 - 72, 2010.

SOARES, A. B; SARTOR, L. R; ADAMI, P. F; VARELLA, A. C; FONSECA, L; MEZZALIRA, J. C. Influência da luminosidade no comportamento de onze espécies forrageiras perenes de verão. Revista Brasileira de Zootecnia. Viçosa, v. 38, n. 3, p. 443 - 451, 2009.

SOUZA, J. A. de. Amostragem de solo, correção e adubação no sistema Integração Lavoura-Pecuária. Belo Horizonte, MG: EPAMIG, 2007, v. 28, p. 80 - 95, set./out. (Informe Agropecuário 240).

SPERA, S. T; SANTOS, H. P. dos; FONTANELI, R. S; TOMM, G. O. Efeito da integração entre lavoura e pecuária, sob plantio direto, em alguns atributos físicos do solo após dez anos. Bragantia. Campinas, v. 69, n. 3, p. 695 - 704, 2010. 